\title{
An Isologous Antigen-Antibody Reaction with Human Neutrophiles, Related to Neonatal Neutropenia *
}

\author{
Parviz Lalezari $\dagger$ and Georgette E. Bernard \\ (From the Department of Hematology, Laboratory Division, Montefiore Hospital and \\ Medical Center, New York, N. Y.)
}

Development of methods for detection of leukocyte antigens has made possible the classification of human leukocytes into different antigenic types, distinct from those of erythrocytes. To date several such antigen systems have been described (1-4). Studies on the distribution of some of these antigens in various blood cells have indicated that they are present in both granulocytic and nongranulocytic cells, as well as in platelets $(5,6)$. It has been shown that these antigens are also present in certain nonhematopoietic tissues, such as placenta, kidney, and lung $(5,7)$.

This study concerns a new leukocyte antigen, the first that appears to be specific for neutrophiles. In 2 unrelated families, this antigen was responsible for maternal immunization during pregnancy, and the subsequent transplacental transfer of the antibody appeared to be responsible for neonatal neutropenia.

\section{Methods}

Antibody sources. Test plasmas used in this study were obtained from 3 multiparous female donors. Maternal plasma DeR was obtained 7 years after the last pregnancy. The first, the third, and the fourth children of this donor had documented neonatal neutropenia and were subjects of a previous publication (8). St plasma was obtained from the mother of a pair of dizygotic twins. The twins were the third and the fourth children of the family, and both had neonatal neutropenia (9). The third plasma, containing a monospecific antibody

* Submitted for publication November 26, 1965 ; accepted August 1, 1966.

Supported by U. S. Public Health Service grant HE 10036-01.

Presented in part. at the Annual Meeting of the American Federation for Clinical Research, May 1965, Atlantic City, N. J., and at the Second International Conference on Histocompatibility Testing, August 1965, Leiden, Holland.

† Address requests for reprints to Dr. Parviz Lalezari, Dept. of Hematology, Montefiore Hospital and Medical Center, New York, N. Y. 10467. designated $\mathrm{Ke}(10)$, was also obtained from a multiparous female, none of whose children ever presented any evidence of neutropenia. This antibody had previously been shown to detect an antigen common to leukocytes, platelets, and several solid tissues. Of these donors only Mrs. Ke had received a tranfusion-1 $U$ of blood 6 years before the present study, 30 years after her last pregnancy.

Blood was anticoagulated with $1 / 100$ th vol of $10 \%$ disodium ethylenediaminetetraacetate (EDTA), and cellpoor plasma was collected after centrifugation at $1,350 \mathrm{~g}$ for 30 minutes. Plasma specimens were stored in 1-ml aliquots at $-20^{\circ} \mathrm{C}$.

Cell preparations for agglutination reaction. Leukocyte suspensions were prepared by a method in which hexadimethrine bromide (Polybrene) is used for sedimenting red cells in blood samples anticoagulated by EDTA (11). The leukocyte-rich supernatants were separated from healthy normal blood donors, and the leukocyte counts were adjusted to about 4,000 per $\mathrm{mm}^{3}$ by dilution with autologous cell-poor plasma. Leukocytes with a high proportion of eosinophiles were obtained from patients with various parasitic infestations or the Löffler syndrome. Preparations with a high proportion of lymphocytes were obtained from healthy children under the age of 8 .

Test system. Leukocyte antigen-antibody reactions were studied, by a previously described agglutination method (10), in which serial twofold dilutions of all the test plasmas, were prepared in $0.1-\mathrm{ml}$ vol, with isotonic saline as the diluent. To each dilution, $0.05 \mathrm{ml}$ of leukocyte suspension was added. The results were read microscopically after 5 and 18 hours of incubation at $37^{\circ} \mathrm{C}$. The strength of the agglutination reaction was graded as previously described (10), and the antibody titer was determined as the highest dilution of the test plasma that produced agglutination.

At the end of the incubation period, the incubation mixtures with high lymphocytes or eosinophiles were placed on microscope slides, dried, and subjected to Wright and Giemsa staining for microscopic examination (12).

Cell preparations for absorption. Blood cells were prepared from normal healthy donors as described by Green and Solomon (13). In this method leukocyteplatelet-rich plasma is obtained after dextran sedimentation of red cells. The cells in the supernatant are then sedimented by contrifugation in the narrow part of an "oil bottle," yielding distinct layers of the various 
cell types. Each layer may thus be separately aspirated and resuspended in the donor's own cell-poor plasma. Relatively pure platelet, mononuclear, and granulocyte suspensions can thus be obtained. Platelet preparations were virtually free from other contaminating cells. Separated mononuclear cells, which usually had 5 to $10 \%$ (by volume) platelet contamination, were centrifuged at $350 \mathrm{~g}$ for 15 minutes. This centrifugation, which allowed sedimentation of mononuclear cells while keeping the platelets in suspension, was usually repeated once or twice until the packed cells contained no more than $2 \%$ (by volume) platelets. This was measured by applying the microcapillary method used for the "leukocrit" determination (10) whereby leukocytes and platelets are packed into two macroscopically distinct layers. Thus, it was possible to determine the size of each layer. Differential counts were performed on stained smears of concentrated cell preparations. Mononuclear preparations, which were contaminated by neutrophiles in excess of $12 \%$, as determined by differential counts on 300 cells, were not used. Monocytes and large lymphocytes constituted about one-third of the mononuclear cells, the remaining being small lymphocytes. In the granulocyte layer, red cells represented about $2 \%$ of the packed cell volume, mononuclear cell contamination did not exceed $5 \%$, and platelets were virtually absent.

Although eosinophiles could not be prepared with the same degree of purity as other cells, it was possible to obtain concentrated preparations by use of blood from two nonleukemic patients with eosinophilia. One patient had Löffler's pneumonia; the other had chronic eosinophilia of undetermined origin. In these patients the leukocyte counts were between 20,000 and 40,000 $\mathrm{mm}^{3}, 80 \%$ of which were eosinophiles. The techniques used for cell separation were those described above for preparation of leukocytes, and the final suspensions contained about $80 \%$ eosinophiles.

Solid tissues were processed as follows: Placenta was obtained from the delivery room; liver, kidney, and lung were from autopsies performed not later than 4 hours after death. Tissues were cut into pieces approximately $10 \times 10 \times 2 \mathrm{~mm}$ and were rinsed repeatedly in isotonic saline until the wash solution was grossly clear. The fragments were passed through a 100-mesh stainless steel screen, and the separated cells were suspended and washed three times in $12 \mathrm{ml}$ of normal plasma obtained from male donors who had not received transfusions. For each washing, the cell suspensions were centrifuged at $350 \mathrm{~g}$ for 15 minutes. Leukocyte typing of all tissue donors was determined ante-mortem; with placenta, the agglutination reactions of both maternal and cord leukocytes were ascertained.

Method for absorption and elution. In preliminary experiments, the separated blood cells were adjusted to a "leukocrit" or "thrombocrit" of $15 \%$, a concentration that had been satisfactory in the study of $\mathrm{Ke}$ antibody (10). It soon became evident that with this antigen concentration, DeR antibody was only partially absorbed; for complete absorption, it was necessary to use packed cells. In each experiment, volumes of packed blood or tissue cells, from 0.2 to $1 \mathrm{ml}$, were resuspended in 3 vol of undiluted plasma containing the antibody, and the mixtures were incubated at $37^{\circ} \mathrm{C}$ for 30 minutes. The absorbed plasmas were then separated by 15 minutes of centrifugation at $1,350 \mathrm{~g}$.

For antibody elution, the packed cells obtained after absorption experiments were resuspended and washed five times in $12 \mathrm{ml}$ of isotonic saline. The washed, packed cells were finally resuspended in twice their volume of saline. The cell suspensions were then heated at $56^{\circ} \mathrm{C}$ for 10 minutes and centrifuged at $1,350 \mathrm{~g}$ for 10 minutes in a clinical centrifuge kept at $56^{\circ} \mathrm{C}$ in a heated box. The absorbed plasmas and the eluates were stored at $-20^{\circ} \mathrm{C}$ until used.

DEAE cellulose column chromatography was performed on immune plasmas as previously described (10).

\section{Results}

As determined by DEAE cellulose column chromatography, DeR antibody was mainly in the plasma fractions eluted by $0.02 \mathrm{M}$ phosphate buffer $\mathrm{pH} 6.3$ and corresponding to $\gamma \mathrm{G}$-globulins. The fraction eluted by $1 \mathrm{M} \mathrm{NaCl}$, which contained $\gamma \mathrm{M}$-globulins, had little activity. These findings are illustrated in Figure 1.

\section{Demonstration that DeR antibody detected a single antigen}

Antibody absorption. Aliquots of DeR plasma were absorbed with 14 different $\mathrm{DeR}+$ granulo-

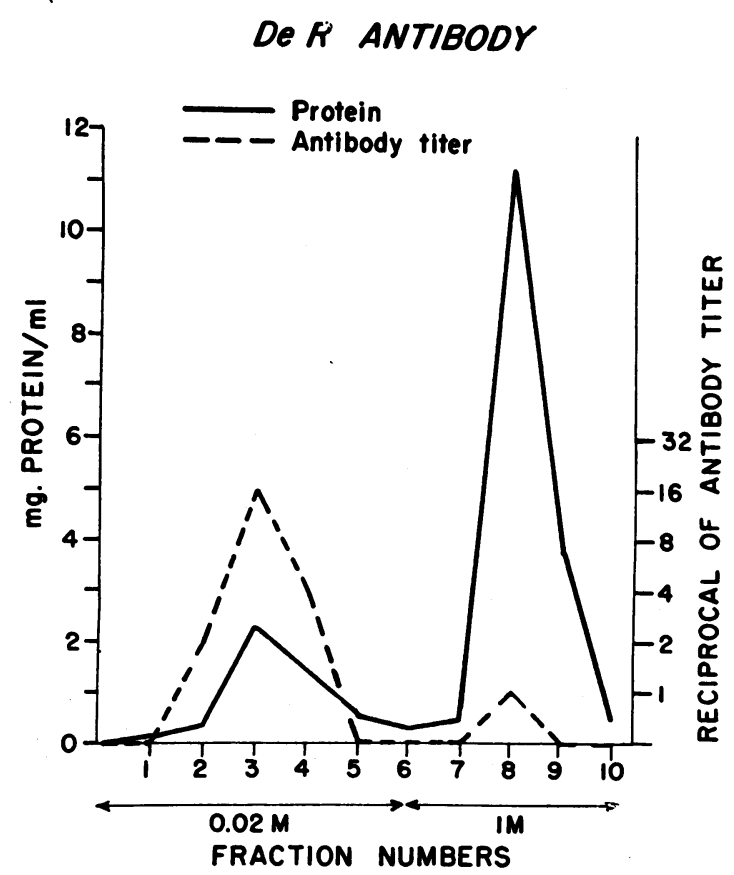

Fig. 1. DEAE CELluLOSE COLUMN Chromatography ON DER PLASMA. 
TABLE I

Absorption of antibody with granulocytes

\begin{tabular}{lrrrr}
\hline \hline & \multicolumn{5}{c}{$\begin{array}{c}\text { Reaction of absorbed plasma } \\
\text { with "positive" leukocytes }\end{array}$} \\
\cline { 2 - 5 } Absorbing & $\begin{array}{c}\text { Total } \\
\text { no. of } \\
\text { cell type }\end{array}$ & $\begin{array}{c}\text { cell } \\
\text { leukocyte } \\
\text { samples } \\
\text { tested }\end{array}$ & $\begin{array}{c}\text { No. } \\
\text { tinglu- }\end{array}$ & $\begin{array}{c}\text { No. not } \\
\text { agglutinated }\end{array}$ \\
\hline DeR + neutrophiles & 14 & 113 & 0 & 113 \\
DeR - neutrophiles & 3 & 31 & 31 & 0 \\
DeR + eosinophiles & 1 & 11 & 11 & 0 \\
DeR - eosinophiles & 1 & 5 & 5 & 0 \\
Ke + eosinophiles & 2 & 15 & 0 & 15 \\
\hline
\end{tabular}

cyte samples, and each absorbed plasma specimen was tested with 4 to 12 different leukocyte samples of the donor panel, making a total of 113 tests. The results of these experiments are given in Table I, which shows that each of the DeR+ granulocyte samples used for absorption completely absorbed the antibody; the absorbed plasmas were nonreactive with all panel members tested. Specificity of antibody absorption was demonstrated by the failure of three different DeR - cells to absorb the antibody.

Antibody elution. Table II shows that antiDeR antibody was eluted only from sensitized $\mathrm{DeR}+$ granulocytes and that the eluates reacted with all DeR+ leukocyte samples tested. The eluted antibody failed to react with $\mathrm{DeR}-$ cells.
TABLE II

Antibody elution from granulocytes sensitized by DeR antibody

\begin{tabular}{cc}
\hline $\begin{array}{c}\text { Granulocyte samples } \\
\text { used for elution }\end{array}$ & $\begin{array}{c}\text { No. of samples } \\
\text { agglutinated by } \\
\text { eluates }\end{array}$ \\
\hline $\begin{array}{cc}12 \mathrm{DeR}+ \\
3 \mathrm{DeR}-\end{array}$ & $\begin{array}{c}63 / 63 \\
0 / 13\end{array}$
\end{tabular}

These data strongly suggest that DeR antibody detects a single antigen.

\section{Incidence of the antigen}

Of 140 normal and unrelated Caucasian donors tested with DeR plasma $79(56 \%)$ gave positive reactions with titers of $1: 4$ to $1: 128$. Antibody titers were reproducible with \pm 1 -tube differences when tested 3 or 4 times.

\section{Distribution of DeR antigen among blood cells}

Blood lymphocytes and monocytes. Antibody titers of DeR plasma determined before and after absorption with blood mononuclear cells are shown in Figure 2. Seven experiments were performed with absorption by the monocyte-lymphocyte preparations from $\mathrm{DeR}+$ donors, in which antibody titrations were performed on the donors' own leukocytes. In one experiment a DeR - donor was used as a control, and the

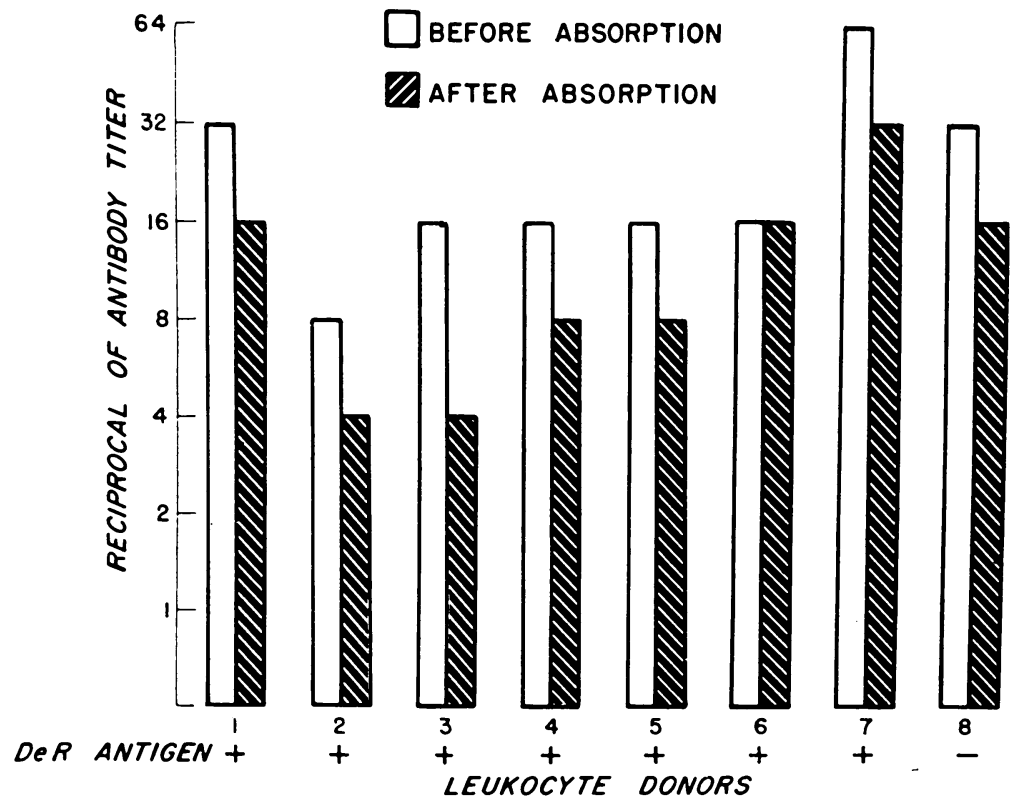

Fig. 2. Antibody absorption by mononuclear Cells. 
titration was performed on DeR+ cells. In each case absorption was followed by insignificant reduction of antibody titer, and the results obtained with DeR+ donors were identical to those with the DeR - donor. Our previously published studies have shown that $\mathrm{Ke}$ antibody was completely absorbed by mononuclear cells (10). No antibody could be eluted from the mononuclear cells used in absorption of anti-DeR plasma. Microscopic examination of the stained slides prepared from agglutinated leukocytes of 5 different $\mathrm{DeR}+$ and $\mathrm{Ke}+$ normal children with high lymphocyte counts revealed that with DeR antibody only neutrophiles participated in the agglutination, whereas lymphocytes remained free. In contrast, with $\mathrm{Ke}$ antibody, all cells participated in the agglutination. These data indicate that blood mononuclear cells do not contain DeR antigen.

A cytotoxicity test $(14)^{1}$ using DeR antiserum and lymphocytes prepared from 50 random donors resulted in no positive reactions. Similarly, dye exclusion tests $(15)^{2}$ failed to reveal cytotoxicity against lymphocytes obtained from 5 DeR+ donors.

Blood eosinophiles. Aliquots of $\mathrm{DeR}$ and $\mathrm{Ke}$ plasmas were absorbed with eosinophile preparations obtained from a DeR+ and a DeR - donor, both of whom were $\mathrm{Ke}+$. The absorbed plasmas were tested against a panel of $\mathrm{DeR}+$ and $\mathrm{Ke}+$ cells. As shown in Table $\mathrm{I}, \mathrm{Ke}$ antibody was removed by the eosinophiles, but $\mathrm{DeR}$ antibody was not.

Microscopic examination of stained slides prepared from agglutinated leukocytes of 5 different $\mathrm{DeR}+$ and $\mathrm{Ke}+$ patients with high eosinophile counts revealed that with DeR antibody, only neutrophiles participated in the agglutination; eosinophiles remained free. With $\mathrm{Ke}$ antibody, indiscriminate participation of all cells was evident. The data thus indicate that blood eosinophiles possess $\mathrm{Ke}$ but not DeR antigen.

Platelets. Platelets prepared from $9 \mathrm{DeR}+$ and 4 DeR- donors failed to absorb antibody, and no antibody was eluted from the platelets used for absorption. Ke antibody, as previously

\footnotetext{
${ }^{1}$ Kindly performed by Dr. Paul Terasaki, Los Angeles, Calif.

2 Kindly performed by Dr. Paul Engelfriet, Netherlands.
}

shown (10), could be absorbed by and eluted from the platelets. It thus appears that $\mathrm{DeR}$ antigen is not present on platelets.

Erythrocytes. Erythrocytes of 5 donors with DeR + leukocytes were used in antibody absorption and elution experiments. The absorption procedure produced no more than a 1-tube change in antibody titers, and no antibody activity could be shown in the eluates.

\section{Distribution of DeR antigen in nonhemopoietic tissues}

Placenta. The results of $\mathrm{DeR}$ and $\mathrm{Ke}$ antibody absorptions are shown in Figure 3 . In the first 5 experiments, both maternal and cord blood leukocytes were DeR+. The sixth experiment represents a case in which the cord cells were reactive, but the mother was negative. In the seventh and eighth cases, both maternal and cord blood leukocytes were DeR-. The plasmas, after absorption with placental cells, were tested with several DeR+ donors. The change in antibody titers was minimal and identical for both DeR+ and DeR - placenta donors. The same placenta preparations were used for absorption of $\mathrm{Ke}$ antibody, and in all cases an antibody titer change of greater than 4 tubes was achieved.

Other body tissues. Similar experiments were performed with kidney, liver, and lung tissues obtained from 2 donors whose leukocytes were both $\mathrm{DeR}+$ and $\mathrm{Ke}+$. Antibody titer changes after absorption by these tissues are shown in Figure 4. The results indicate that liver, kidney, or lung cells obtained from DeR + donors failed to absorb the antibody. In contrast, $\mathrm{Ke}$ antibody was absorbed by both kidney and lung cells and partially by liver cells. Elution studies showed that only $\mathrm{Ke}$ antibody could be recovered from the absorbing cells, and all cells from $\mathrm{Ke}+$ donors had this property. These data suggest that none of the tissues tested contained DeR antigen.

Since DeR antigen might have been present in various tissue cells in quantities too small to absorb a significant amount of the antibody, absorption studies with the following modifications were undertaken: Serial dilutions of DeR plasma, from $1: 2$ to $1: 16$ were prepared, normal plasma being used as the diluent. An aliquot from each dilution was absorbed with $\frac{1}{3}$ vol of packed cells 


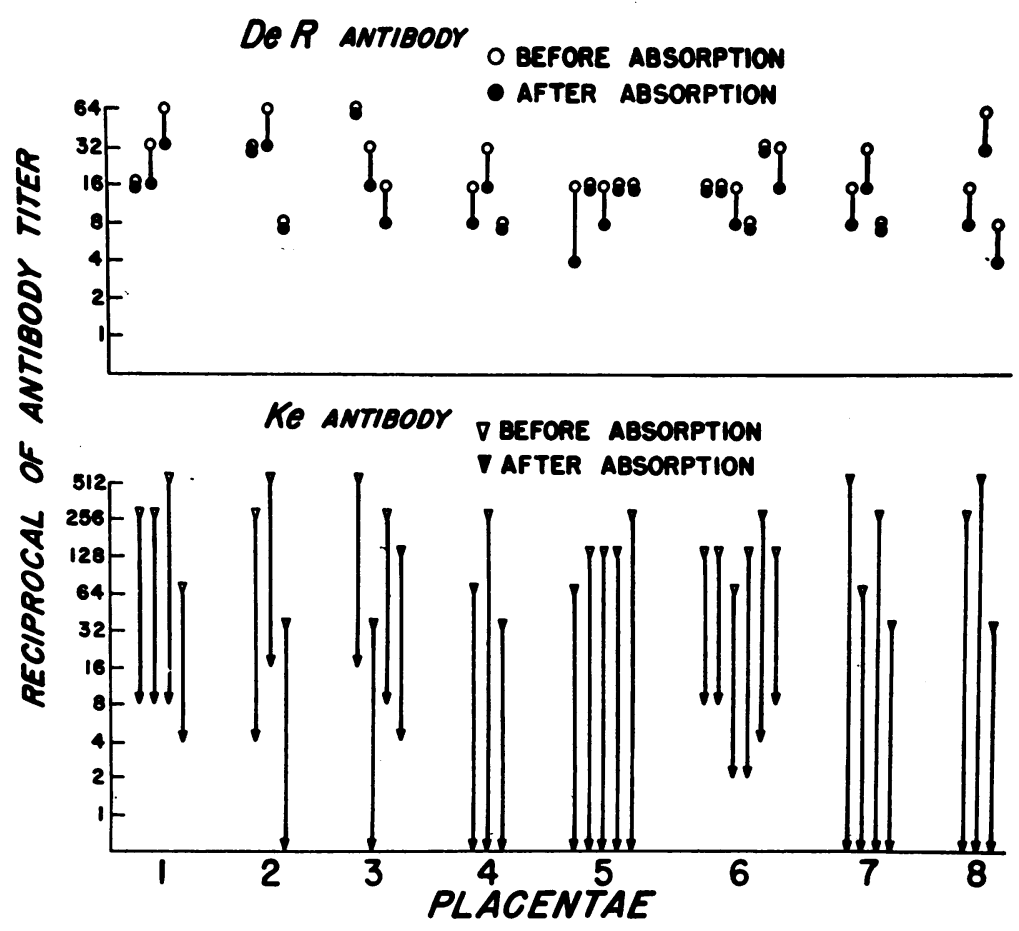

Fig. 3. Comparison of DeR with Ke ANtibody AFter AbSORPtion by PLACENTAL CELLS.

that were prepared from kidney, lung, and the liver of a DeR+ tissue donor. No changes greater than 1 tube in the antibody titers were observed in any of the plasma dilutions used. In addition, aliquots of undiluted DeR plasma were subjected to 3 consecutive absorptions, each time with $\frac{1}{3}$ vol of packed liver, kidney, and lung cells. This procedure did not produce any change in the antibody titer, and no antibody was eluted from the cells used for absorption. Similar observations were made when packed platelets were used.

In an experiment in which a blood mononuclear preparation with granulocyte contamination of about $1 \%$ was used, no antibody titer changes were produced by absorption when DeR plasma was diluted $1: 2$ and $1: 8$ before absorption. In 2 other experiments, a 1:8 dilution resulted in complete removal of the antibody, presumably due to contaminating neutrophiles that were present in excess of $7 \%$.

\section{Properties of St antibody}

The titer of St antibody ranged from $1: 2$ to $1: 16$ with leukocytes obtained from various do- nors. As described for DeR plasma, St plasma was also subjected to DEAE cellulose column chromatography, and antibody activity was mainly found in $\gamma$ G-globulin fractions. Distribution of the antigen in various blood cells and body tissues was also studied. As shown in Figure 5, St antibody was absorbed only by neutrophiles. By elution techniques antibody activity was recovered only from absorbing neutrophiles. It was also demonstrated that eosinophiles and lymphocytes did not participate in the agglutination of the neutrophiles produced by St antibody.

To test whether both DeR and St antibodies detected the same antigen, we determined the reaction patterns of each in 100 unrelated and randomly selected leukocyte donors. With the exception of the strength and the titer of reaction, for both antibodies identical results were obtained. The reaction patterns produced by DeR and St antibodies were similar when leukocytes of the members of both families were tested. Cross absorption of DeR and St plasmas showed that the antibodies for both were completely removed by the leukocytes obtained from the father of each family. Similarly, DeR and St anti- 


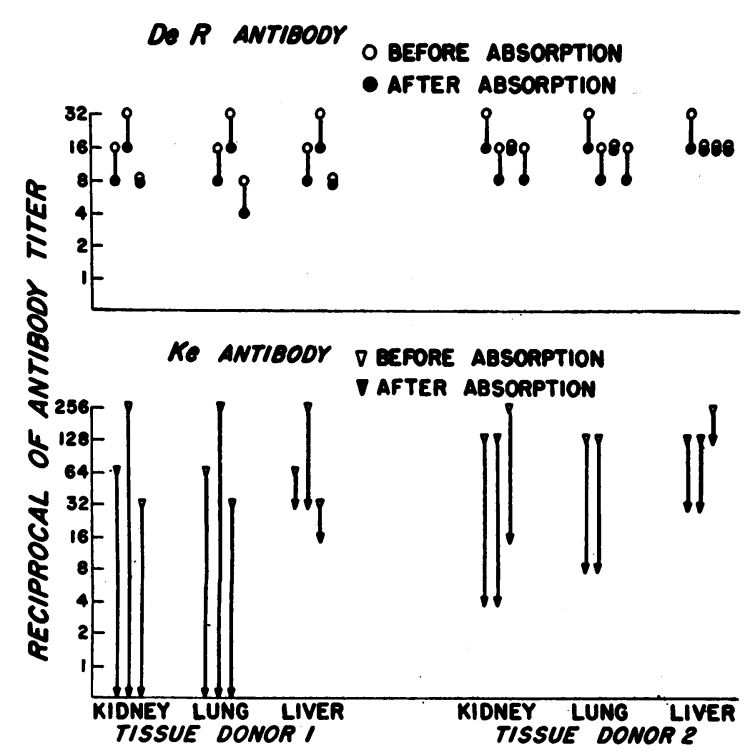

Fig. 4. DER AND KE ANTIBODY ABSORPtion BY TISSUES OF TWO DIFFERENT DONORS. Although $\mathrm{Ke}$ antibody absorption by the liver cells appears insignificant, the antibody was eluted from all the absorbing tissue cells. In contrast, DeR antibody was not eluted from any of the tissues used for absorption.

bodies eluted from each of these cell preparations agglutinated the leukocytes of both fathers.

These data suggest that similar to DeR, St antibody reacts only with neutrophiles and that both detect the same antigen.

Variation in the antibody titers found with different leukocyte donors raised the possibility that the observed phenomenon might represent a dose effect. Family members of donors whose leukocytes gave negative reactions, or those which strongly reacted with one of the antibodies, were studied. The leukocyte preparations were simultaneously tested with DeR and St plasmas. The results are shown in Figure 6. It was found that both antibodies invariably showed a parallel reactivity with each donor, but the titer with $\mathrm{St}$ antibody was 2 to 3 tubes less than that obtained for DeR.

\section{$D e R$ and other leukocyte antigens}

During the Second International conference and workshop on tissue typing held in Leiden, Holland, in August 1965, DeR plasma and 76 other antileukocyte antisera were tested against a panel of 40 leukocyte donors. The antisera used in this study were provided from different laboratories and were presumed to be monospecific. These antisera identified most of the previously known leukocyte antigens. To evaluate possible relationships between the antigens identified by these sera, we compared the reaction patterns produced by each with the aid of a computer. DeR plasma revealed a positive correlation to only one antiserum, B/14. ${ }^{3}$ This antibody had been produced by active immunization in a hematologically normal subject, by repeated injections of ${ }^{3}$ Kindly supplied by Dr. Ruggero Ceppellini.

\section{St ANTIBODY}

\section{DBEFORE ABSORPTION WIA AFTER ABSORPTION}
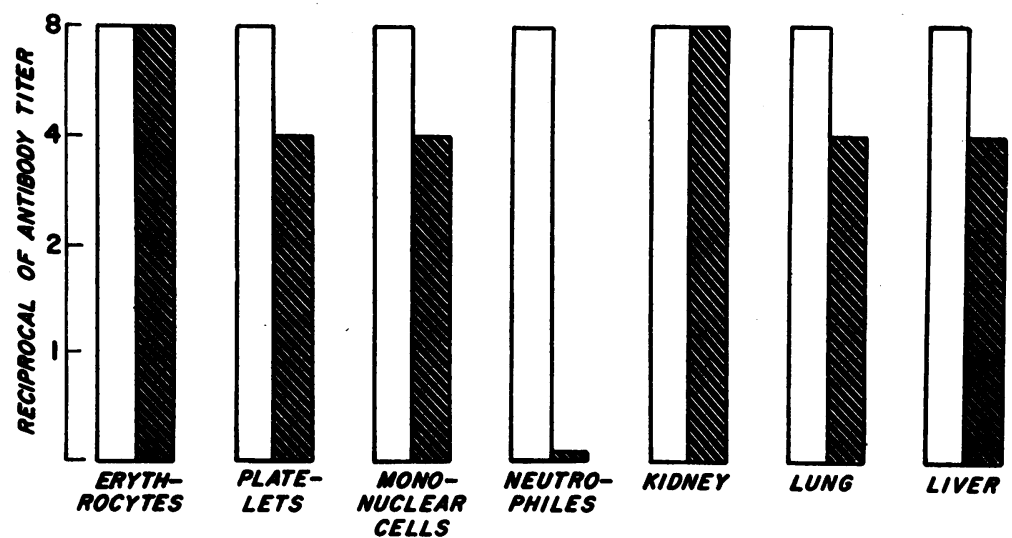

Fig. 5. Antibody absorption studies on St plasma. 

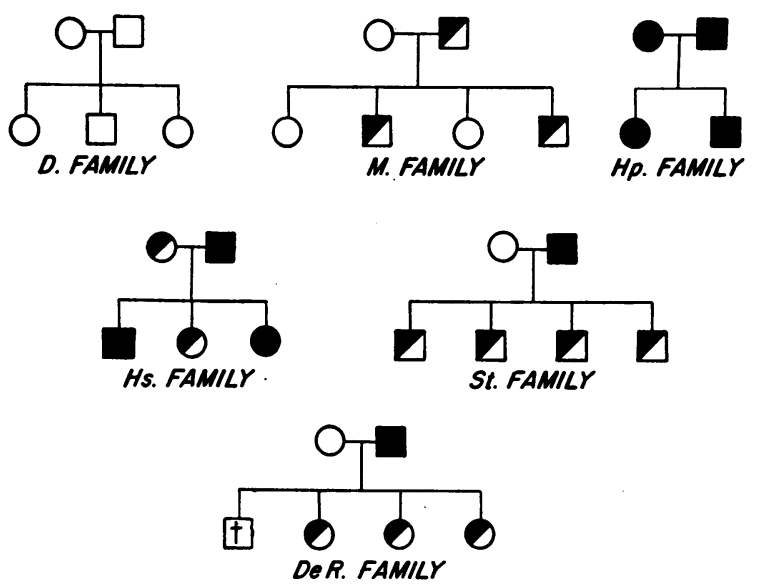

Fig. 6. Family studies USING Both DeR aNd St ANTIBODIEs. Solid figures indicate "strong" reactors; half-shaded figures indicate "weak" reactors; unshaded figures represent nonreactors. $\dagger$ indicates the deceased member.

leukocytes obtained from selected donors (16). Ceppellini, Mattiuz, and Curtoni had shown with the EDTA agglutination method that, similar to most of the earlier serum samples obtained from the immunized subject $(\mathrm{Bu}), \mathrm{B} / 14$ detected a single antigen with a frequency of $58 \%$ in the Italian population (16). By a cytotoxicity test, however, B/14 contained a mixture of antibodies, different from the agglutinin, with prevalent anti$4^{2}$ activity (17).

Further agglutination studies performed in this laboratory revealed similar specificity for DeR and $\mathrm{B} / 14$ antisera with 20 additional leukocyte donors. The only difference was in the much higher titer obtained with $\mathrm{B} / 14 .^{3}$ The distribution of antigen detected by $\mathrm{B} / 14$ was also studied, and as shown in Figure 7, it was found that the antibody was absorbed only by blood neutrophiles; no antibody absorption was achieved by red cells, platelets, mononuclear cells, or kidney, lung, or liver cells. These observations were reproduced by the use of platelets from 3 different sources and tissues of 2 different donors. It was also found that blood lymphocytes and eosinophiles did not participate in neutrophile agglutination produced by $\mathrm{B} / 14$ antibody. Mattiuz and Ceppellini have recently confirmed these findings; they have shown that lymphocyte suspensions obtained from $\mathrm{BU}+$ donors did not absorb EDTA agglutinins (17).

\section{Discussion}

The data presented above indicate the identification of an antibody directed against an antigen that is unique to neutrophilic leukocytes. A single antigen was evidently detected, as illustrated by two different test systems: Absorption studies with DeR+ leukocytes caused complete removal of DeR antibody by each of a panel of leukocyte donors; plasma so absorbed failed to react with leukocytes from numerous unrelated DeR+ subjects. Eluted antibody from each individual leukocyte preparation reacted with all the leukocyte samples with which the unabsorbed plasma reacted, and the previously negative sam-

\section{$\square$ BEFORE ABSORPTION \\ W/, AFTER ABSORPTION}
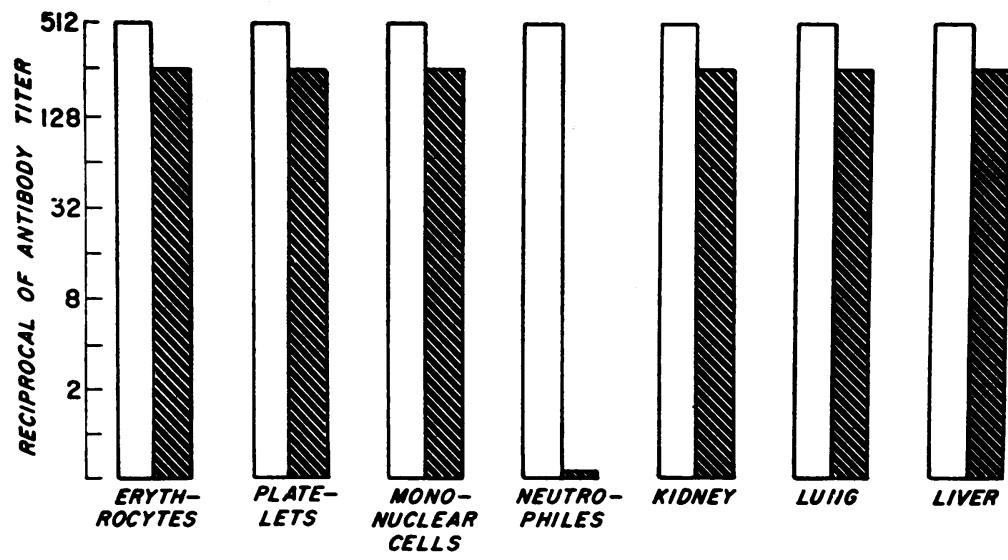

Fig. 7. Antibody ABSoRption studies on B/14 Antibody. 
ples remained negative. These findings are in contrast to those obtained with plasmas from multitransfused patients, which contained multiple antibodies against several different leukocyte antigens. When these "complex" antibodies were completely absorbed with leukocytes from a single donor, residual antibody activity remained that was active against cells from most other unrelated donors (10).

The finding of concordant reactions produced by both DeR and St plasmas in 100 different donors indicates that both plasmas detect the same antigen ( $\mathrm{p}<0.0001$ by the $x^{2}$ method). This interpretation is further supported by DeR and St family studies, in which the two maternal leukocyte preparations were nonreactive and the paternal cells strongly reacted with both antibodies. Furthermore, when the two antisera were absorbed with the paternal cells of one family, they both became nonreactive with the paternal cells of the other family, and the antibody eluted from these absorbing cells had identical specificity.

The antigen demonstrated by $\mathrm{DeR}$ and $\mathrm{St}$ antibodies appears to be identical to the antigen detected by the leukocyte agglutinin present in B/14 antiserum, an antibody experimentally produced by Ceppellini and his associates. This neutrophile-specific isoantibody produced by an immunization route other than transplacental is a helpful adjunct to the present observations.

The DeR antigen system may be composed of two or more alleles. Since $56 \%$ of the population reacts with the antibody, DeR and its allele would have gene frequencies of 0.56 and 0.44 , respectively, were the alleles limited to two. Twelve per cent of the population would be DeR homozygous and $44 \%$ heterozygous. Confirmation of these values awaits discovery of the allelic antigen. The results of the family studies suggest a genetic pattern, and although our effort to find an antibody that may detect the postulated allele has thus far been unsuccessful, the family data obtained are consistent with the hypothesis that the strength of the reaction is related to the antigen dose. Leukocytes of presumed heterozygotes were less reactive than cells of presumed homozygotes. This phenomenon, however, may also be due to augmentation by an unrelated gene. Although observation of a dose effect from leuko- cyte antigens has not been previously reported, this phenomenon is well known to occur with the red cells $(18,19)$.

The most convincing criterion for establishing antigenic determinants is demonstration of specific absorption and elution of the corresponding antibody. By these techniques, we have found no evidence of DeR antigen activity in any of the studied cells except polymorphonuclear neutrophiles. The possibility remains, however, that the antigen is present in these tissues in a modified form not readily reactive with the antibody or in a concentration not detected by the methods used. The latter possibility seems unlikely, since no progressive fall in the antibody titer occurred after repeated absorptions. Neither was the antibody activity removed when it was diluted before absorption. In contrast to $\mathrm{DeR}, \mathrm{Ke}$ antibody was removed by the absorption procedures. Although there has been no opportunity to use $\mathrm{Ke}$ - tissue cells as a control, it has been demonstrated that $\mathrm{Ke}$ antibody absorption is highly specific in that granulocytes, mononuclear cells, and platelets obtained from $\mathrm{Ke}-$ donors do not absorb antibody (10). The demonstration of $\mathrm{Ke}$ antigen on the same cell preparations used in this study indicates that at least some cell antigens were not destroyed by the procedures employed, and in the preparations with high eosinophiles no evidence of antigen alteration due to the underlying disease was found. Although it has been shown that agglutinating antibodies are not necessarily cytotoxic $(14,17)$, the failure of DeR antibody to exert cytotoxicity on lymphocytes is an observation in agreement with the conclusion that DeR antigen is not present on lymphocytes. Distribution of leukocyte antigens in granulocytes and lymphocytes has been studied $(5,15,20)$. According to these reports, suggestive evidence indicates that granulocytes and lymphocytes may have antigenic differences. With the discovery of specific leukocyte groups, it has been shown that antigens of groups 4 and 5 are present on granulocytes, lymphocytes, platelets, and several tissues including kidney, placenta, skin, lung, and spleen $(1,5)$. An additional system of leukocyte antigens, designated LA, has also been found in lymphocytes and platelets (6). Shulman, Marder, Aledort, and Hiller have described a lymphocyte-specific antigen (21). Thus, 
DeR antigen is unique to date in its specific localization to neutrophiles. The present study demonstrates that within a group of closely related cells such as eosinophiles and neutrophiles, antigenic differences may exist. This finding does not imply different origins for these cells, but may rather be related to specialized cell functions.

The observation that DeR antigen is confined to neutrophiles corresponds to laboratory findings in the affected children with neonatal neutropenia, who showed transient but specific absence of neutrophiles in their peripheral blood and bone marrows, with preservation of other blood elements $(8,9,22)$. Identification of the same antigen, responsible for the development of maternal antibodies and the subsequent occurrence of neonatal neutropenia in two unrelated families, supports the concept that a similar immune mechanism was involved in both cases. It was also shown that both antibodies were primarily $7 \mathrm{~S}$ globulins, proteins capable of crossing the placenta. These findings may offer an explanation for the rarity of this entity: Significant neutropenia occurred when the involved antigen was limited to neutrophiles. In contrast, antibodies to leukocyte antigens with wide blood and tissue distribution do not produce leukopenia. If maternal antibodies to the latter type of antigens cross the placenta, they may be absorbed by various tissues to such a degree that their effects on neutrophiles are negligible. Thus, investigators (22-24) who failed to find neonatal neutropenia in babies born to mothers who had leukocyte antibodies may have been working with antibodies having a broad spectrum of cell reactivity.

The incidence of maternal immunization against various leukocyte antigens may be related to their tissue distribution. Mothers are more likely to become immunized against ubiquitous antigens when antigenic stimuli arise from fetal cells other than leukocytes, and even placental cells. On the other hand, for immunization against fetal-specific neutrophile antigens, the antigenic stimulus can derive only from fetal neutrophiles. In view of these considerations, many maternal leukocyte antibodies may be eliminated as potential sources of neonatal neutropenia.

Whether specific cell antigens are significant in homograft rejection is unknown, but their pres- ence suggests that this potential source of incompatibility should be explored.

\section{Summary}

A leukocyte antigen is described that is unique to blood neutrophiles and appears to be involved in the pathogenesis of neonatal neutropenia. The antigen was identified by a leukocyte agglutinin found in plasmas of 2 unrelated mothers, each of whom had several newborns with isoimmune neonatal neutropenia. The antibodies were demonstrated to be primarily $\gamma \mathrm{G}$-globulins. Evidence was obtained to indicate that antibodies of both mothers identified the same antigen. Cross absorption and antibody elution studies demonstrated that a single antigenic determinant with a gene frequency of 0.56 was involved. Antibody absorption and elution were achieved only by neutrophiles. The antigen was not found on red cells, platelets, mononuclear cells, eosinophiles, placenta, or lung, liver, or kidney cells. This antigen distribution correlates with the selective neutropenia observed in the affected newborns. We suggest that this specific localization of the antigen is essential for the occurrence of neonatal neutropenia and that leukocyte antibodies directed against widely distributed antigens are not likely to affect the neutrophiles of the newborn.

\section{Acknowledgments}

The authors wish to thank Drs. Theodore H. Spaet, Richard Rosenfield, and Evelyn Gaynor for their assistance in preparation of this manuscript.

\section{References}

1. Van Rood, J. J., and A. Van Leeuwen. Leukocyte grouping. A method and its application. J. clin. Invest. 1963, 42, 1382.

2. Van Leeuwen, A., J. G. Eernisse, and J. J. Van Rood. A new leukocyte group with two alleles: leukocyte group five. Vox Sang. (Basel) 1964, 9, 431.

3. Payne, R., M. Tripp, J. Weigle, W. Bodmer, and J. Bodmer. A new leukocyte isoantigen in man. Cold Spr. Harb. Symp. quant. Biol. 1964, 29, 285.

4. Bruning, J. W., A. Van Leeuwen, and J. J. Van Rood. Leukocyte antigens in Histocompatibility Testing 1965. Copenhagen, Munksgaard, 1966, pp. 275-84.

5. Van Rood, J. J. Leukocyte grouping. A method and its application. Thesis, University of Leiden, 1962.

6. Bialek, J. W., W. Bodmer, J. Bodmer, and R. Payne. Distribution and quantity of leukocyte antigens in 
the formed elements of the blood. Transfusion (Philad.) 1966, 6, 193.

7. Amos, D. B., and N. Peacocke. Leukoagglutination. A modified technique and preliminary results of absorption with tissues. Proceedings of the 9th Congress of the European Society of Haematology, Lisbon, 1963. Basel/New York, S. Karger, 1963, pp. $1132-40$.

8. Lalezari, P., M. Nussbaum, S. Gelman, and T. H. Spaet. Neonatal neutropenia due to maternal isoimmunization. Blood 1960, 15, 236.

9. Hanna, M. Personal communication.

10. Lalezari, P., and G. E. Bernard. Identification of a specific leukocyte antigen: another presumed example of $5^{\mathrm{b}}$. Transfusion 1965, 5, 135.

11. Lalezari, P. A new technic for separation of human leukocytes. Blood 1962, 19, 109.

12. Lalezari, P., and T. H. Spaet. Studies on the genetics of leukocyte antigens. Blood 1959, 14, 748.

13. Green, I., and W. Solomon. Separation of human lymphocytes and monocytes using an "oil bottle." J. clin. Path. 1963, 16, 180.

14. Terasaki, P. I., and J. D. McClelland. Microdroplet assay of human serum cytotoxins. Nature (Lond.) 1964, 204, 998.

15. Engelfriet, C. P., and V. P. Eijsvoogel. Cytotoxic iso-antibodies against leukocytes. Vox Sang. (Basel) 1965, 10, 228.
16. Ceppellini, R., P. L. Mattiuz, and M. Curtoni. Characteristics and evolution of leukoagglutinins developed in a patient receiving multiple transfusions from selected donors in Histocompatibility Testing. Washington, D. C., National Academy of ScienceNational Research Council, 1965, pp. 71-82.

17. Mattiuz, P. L., and R. Ceppellini. Personal communication

18. Stratton, F., and P. H. Renton. Practical Blood Grouping. Oxford, Blackwell, 1958, p. 175.

19. Race, R. R., and R. Sanger. Blood Groups in Man, 4th ed. Philadelphia, F. A. Davis, 1962, p. 4.

20. Walford, R. L. Leukocyte Antigens and Antibodies. New York, Grune \& Stratton, 1960, p. 66.

21. Shulman, N. R., V. J. Marder, L. M. Aledort, and M. C. Hiller. Complement-fixing isoantibodies against antigens common to platelets and leukocytes. Trans. Ass. Amer. Phycns 1962, 75, 89.

22. Dausset, J., and G. Malinvaud. Les agranulocytoses et granulopénies néo-natales par iso-immunisation foetomaternelle. Nouv. Rev. franc. Hémat. 1964, 4, 154.

23. Payne, R., M. R. Rolfs, M. Tripp, and J. Weigle. Neonatal neutropenia and leukoagglutinins. Pediatrics 1964, 33, 194.

24. Jensen, K. G. Leukocyte antibodies in serums of pregnant women. Vox Sang. (Basel) 1962, 7, 454. 